\title{
Sociologia da Educação Superior nos Contextos Internacional, Regional e Local*
}

José Joaquín Brunner

Em memória de Luis Scherz

\section{ORIGEM E DESENVOLVIMENTO DO CAMPO NOS PAÍSES CENTRAIS}

\begin{abstract}
sociologia da educação superior é um campo acadêmico relativaA mente novo (Gumport, 2007). Surge nos Estados Unidos no fim da Segunda Guerra Mundial. Inicialmente, abarca quatro áreas de pesquisa: duas principais e duas menores, conforme o balanço realizado por Clark (1973) no começo dos anos 1970. As áreas principais abrangem o estudo das desigualdades educacionais após o ensino médio e a análise dos efeitos psicossociais da experiência universitária. As áreas menores incluem o estudo da profissão acadêmica, a organização das instituições e os sistemas de educação terciária como unidades de estudo. Com base nessas quatro áreas, o campo evolui em múltiplas direções a partir de 1970 (Brennan e Teichler, 2008; Teichler, 2007; Kogan, 2000).
\end{abstract}

Em primeiro lugar, estende-se geograficamente para abarcar, com diversos graus de solidez institucional e em diferentes temporalidades,

\footnotetext{
* Este artigo foi escrito no marco do Programa de Investigación en Políticas de Educación Superior, do II Concurso de Anillos de Investigación en Ciencias Sociales, da Comisión Nacional de Investigación Científica y Tecnología (Conicyt), e conta com o apoio da Cátedra Unesco (Organização das Nações Unidas para a Educação, a Ciência e a Cultura) de Políticas Comparadas de Educación Superior com sede na Universidade Diego Portales. [A tradução do original em espanhol "Apuntes sobre Sociología de la Educación Superior en Contexto Internacional, Regional y Local" é de Renata Oliveira Rufino.]
}

DADOS - Revista de Ciências Sociais, Rio de Janeiro, Vol. 52, nํ3, 2009, pp. 621 a 658. 
as demais regiões do mundo, partindo da Europa Ocidental (onde antes Durkheim e Weber se haviam ocupado da educação e das universidades) e estendendo-se em seguida ao Canadá e aos países anglófonos desenvolvidos do Pacífico, à América Latina, à Europa Central e ao Leste Europeu, à Ásia, aos países árabes e, mais recentemente, à África. Em nenhum lugar, no entanto, o campo alcança um grau de institucionalização como o que havia conseguido precocemente nos Estados Unidos, por exemplo, por meio de núcleos estáveis de pesquisa em várias das principais universidades desse país e de programas de pósgraduação, em especial de doutorado.

Posteriormente, a organização do campo também se torna mais complexa pela inclusão de novos temas, tópicos e assuntos de pesquisa nas quatro áreas identificadas por Clark no início dos anos 1970. A divisão do trabalho se fragmenta, especializa-se e dá origem a uma multiplicação das linhas de pesquisa e de reflexão.

A área de estudo das desigualdades no âmbito da educação terciária se amplia para incluir temas variados e novos tópicos de indagação (McDonough e Fann, 2007): esquemas de apoio estudantil, tópico que alcança com Johnstone (2006) o estatuto de um programa global de pesquisa $^{1}$; políticas nacionais e institucionais de acesso, assunto que, com a massificação do ensino superior, adquire importância crescente; habilidades e conquistas dos estudantes que têm acesso à educação superior e os procedimentos para sua seleção; escolha de instituições e de programas, e os determinantes da demanda estudantil; status socioeconômico das famílias, estudantes não tradicionais, diversificação da demanda e participação de minorias nos estudos superiores. Entre essas linhas, a de maior impacto intelectual se refere às pesquisas de Bourdieu, em especial aquelas incluídas em seus livros Os Herdeiros (Bourdieu e Passeron, 1964) e A Nobreza de Estado (Bourdieu, 1989). Em relação às políticas, o principal efeito se deve às análises sobre modalidades de financiamento e de apoio estudantis.

Os estudos sobre o impacto da experiência universitária na socialização dos estudantes passam por uma ampliação similar. Embora uma parte importante dessas pesquisas tenha lugar dentro da disciplina da psicologia, elas se desenvolvem habitualmente em um marco de premissas proveniente da sociologia (Hurtado, 2007). Nesse marco, são analisados particularmente fenômenos relativos à retenção e à deserção, à socialização estudantil, à aquisição de competências durante os 
cursos de graduação, ao efeito dos pares e suas ramificações em direção às políticas e práticas de admissão, ao impacto de variáveis contextuais, como o tamanho das instituições, a seus níveis de seletividade e à composição social dos alunos. Aqui adquirem particular importância os estudos norte-americanos sobre a seleção de estudantes e a "seletividade" das instituições (Winston, 2003; 2000; 2000a), em estreita relação com os temas bourdianos da reprodução social das desigualdades (Brunner e Uribe, 2007:parte 2).

Ao mesmo tempo, a profissão acadêmica passa, durante as últimas décadas, de uma área menor - como o era nos tempos de Wilson (1942) e Caplow e McGee (1958) - para uma área maior, em que a autoridade, o trabalho e os valores dos acadêmicos são analisados seja em perspectiva nacional, seja em perspectiva comparada. Clark (1983) publica, no fim da década de 1980, seu livro sobre os "pequenos mundos, mundos diferentes" dos acadêmicos, no qual estuda as dimensões da profissionalização acadêmica, a divisão do trabalho disciplinar, a integração e a identidade da profissão. Em meados da década seguinte, Altbach (1996) edita um volume sobre a profissão acadêmica no âmbito internacional, incluindo estudos sobre países desenvolvidos da Ásia, da Austrália, de três nações latino-americanas (Brasil, Chile e México), de países da Europa Ocidental, Rússia e Israel. Recebem também particular atenção nas publicações as elites entre os professores. Clark (1977) as estuda sob o nome de "oligarquias acadêmicas" no caso da Itália; Ringer (1995) utiliza a denominação de "mandarins" no caso da Alemanha; Halsey (1995) as analisa em relação ao declínio dos "dons" nas universidades inglesas tradicionais; e Altbach (2002) dedica um volume à queda dos "gurus" acadêmicos em vários países em desenvolvimento. Os processos de profissionalização acadêmica precária em países em desenvolvimento com rápida massificação da matrícula também mereceram atenção, especialmente no México (Álvarez, 2004; Grediaga, Rodríguez e González, 2004; Gil Antón et alii, 1994). Mais recentemente, o surgimento de grupos de administração acadêmica começou a ser objeto de estudo nessa área (Rhoades, 2007:129), em particular do ponto de vista das relações mutáveis de poder entre esses grupos e os acadêmicos que realizam as atividades de base da universidade (Deem, 2004; 2001; 2001a).

A análise da universidade como organização também experimentou uma evolução similar, passando de área menor dentro da literatura especializada para área maior e em constante crescimento. De fato, como 
mostra Peterson (2007), não só se multiplicaram os modelos (colegial, burocrático, profissional, político, empresarial, gerencial etc.) mediante os quais se tenta explicar a organização dessas instituições. Eles se ampliaram também pela consideração de variáveis endógenas e exógenas dos sistemas (Brunner, 2007a), pela inclusão de fatores econômicos e políticos do contexto nacional, pela análise da educação superior como indústria, ou seja, do ponto de vista das organizações industriais e de sua adaptação às novas condições do mercado global (Marginson e Van der Wende, 2006). Certamente foi esta a área-macrossociologia e economia política da educação superior - que teve maior desenvolvimento durante as últimas duas décadas, como mostra a abundante produção escrita em diversas regiões do mundo. Na esfera internacional, destacam-se os trabalhos realizados pelo Center for Higher Education Policy Studies (Cheps), da Universidade de Twente, na Holanda ${ }^{2}$.

Em terceiro lugar, após 1970, as aproximações ao estudo da educação superior começam a enfatizar cada vez mais a interdisciplinaridade, isto é, a abordagem de seus objetos de pesquisa com base em diversas e variáveis combinações disciplinares - algo que também ocorre no campo dessa sociologia especializada. Por exemplo, Clark e Neave (1992), na Enciclopédia da Educação Superior editada no início dos anos 1990, identificam ao menos dezessete "perspectivas disciplinares" que, nesse momento, confluíam no estudo da educação superior: 1) administração pública; 2) antropologia; 3) ciências políticas; 4) economia política; 5) estudos comparados; 6) estudos das ciências; 7) o estudo específico da educação superior como campo acadêmico; 8) estudos da mulher; 9) direito; 10) filosofia; 11) história; 12) literatura; 13) micro e 14) macrossociologia; 15) o enfoque de políticas públicas; 16) psicologia social; 17) teoria das organizações. Pela mesma razão, a produção desse campo - embora conte com um número de revistas próprias, especificamente dedicadas à pesquisa da educação superior - se canaliza também por uma série de outras revistas pertencentes a essas diferentes disciplinas e enfoques. O campo específico se torna cada vez mais híbrido, e seus limites internos, em relação aos campos adjacentes, cada vez menos nítidos.

Em quarto lugar, tal confluência de diversos pontos de vista, perspectivas disciplinares e enfoques, além de levar a uma maior diferenciação em cada campo e subcampo, e gerar o caráter híbrido de todos eles ao abordar a educação terciária, é pressionada também, desde dentro do próprio sistema, pela diferenciação e interação entre objetivos pura- 
mente acadêmicos (produção de conhecimento publicada em revistas especializadas e registradas internacionalmente) e objetivos práticos orientados para formulação e execução de políticas na esfera dos sistemas nacionais e das instituições e sua gestão. Em outras palavras, participam de modo conjunto, nesse campo, pesquisadores especializados e um grupo crescente de agentes, ou seja, docentes, pesquisadores não especialistas e, sobretudo, dirigentes da gestão universitária que refletem sobre suas práticas. Aqui aparecem com especial força as recomendações e os estudos realizados pela Unesco, pelo Banco Mundial e, especialmente, pela Organização para Cooperação e Desenvolvimento Econômico (OCDE).

Enquanto alguns acolhem essa tensão de forma positiva, como causadora de efeito inovador sobre a produção de conhecimento, outros consideram que ela opera como obstáculo para o desenvolvimento de um programa autônomo de pesquisa no campo, impedindo a construção de teorias que forneçam consistência disciplinar específica. Há também os que observam que a tensão entre teoria e prática introduz uma fissura no campo que, no fim, prejudica tanto seu desenvolvimento acadêmico como sua capacidade de responder aos interesses dos agentes que dirigem as instituições universitárias. Como apontou recentemente Clark (2007), a principal figura acadêmica de nosso campo,

[...] já não há dúvida sobre isto: a desconexão entre pesquisadores e agentes em relação à compreensão sobre as universidades continua sendo grande. Os pesquisadores escrevem principalmente para outros pesquisadores, armados de suas perspectivas disciplinares e interdisciplinares. Já no início de suas carreiras examinam hipóteses geradas a partir da literatura. À medida que envelhecem, aspiram a gerar "teoria" expressa em linguagem inflada e pomposa. Cogitando dentro de amplos esquemas, como ocorre atualmente na sociologia da educação superior, publicam artigos em revistas que os agentes não leem. Os agentes, por outro lado, buscam entre si caminhos para lidar com as preocupações específicas de sua atividade cotidiana. Para eles, a teorização acadêmica parece imprecisa e remota; uma manifestação a mais das linguagens em voga, distante das complicações de qualquer operação local. Os pesquisadores apontam alto demais e tentam explicar demais. Os agentes [...] apontam muito baixo e caem em discussões ad hoc. Quando surgem perguntas sobre como as universidades se transformam, essa brecha aumenta ainda mais (ibidem:319). 
Em quinto lugar, esse campo híbrido e pressionado internamente evolui pela aparição de novos temas, os assuntos emergentes. Assim, por exemplo, em uma coleção de artigos dedicados à sociologia contemporânea da educação superior (Gumport, 2007a), são mencionados, entre outros, a educação superior como instituição social e seu trajeto, desde as formas modernas (para abreviar, os modelos napoleônico e humboldtiano) até as formas adotadas com a globalização (Meyer et alii, 2007); o estudo sociológico dos departamentos acadêmicos como unidades de base das instituições universitárias (Hearn, 2007); a análise da diversidade dentro das universidades e seu impacto nas sociedades multiculturais (Antonio e Muñiz, 2007); e a centralidade adquirida atualmente pelo estudo das políticas de educação superior como especialidade por mérito próprio (Bastedo, 2007). Esse registro de assuntos emergentes, porém, é altamente específico para o contexto da educação superior dos Estados Unidos.

Se tomarmos um horizonte geográfico mais amplo, esses temas podem se multiplicar sem dificuldade: dinâmicas de transformação das universidades públicas, tópico de ampla difusão em diferentes lugares do mundo; emergência das universidades privadas e seu lugar nos sistemas nacionais; esquemas, procedimentos e práticas para garantir a qualidade na educação superior; relação entre sistemas de ensino superior e mercado de trabalho; internacionalização das universidades, comércio transnacional de serviços de educação terciária e mobilidade estudantil na esfera internacional; novas modalidades de financiamento das universidades e seu impacto sobre a gestão institucional; culturas das "tribos acadêmicas" (Becher, 2001) e, em geral, análise cultural da educação superior (Välimaa e Ylijoki, 2008; Mollis, 1995); novos modos de produção de conhecimento conhecidos na literatura pela denominação "modo de produção dois" (MP2), em contraposição ao "modo de produção acadêmico" (Nowotny, Scott e Gibbons, 2001); mercados universitários (Brunner e Uribe, 2007) e dinâmicas de mercantilização em diferentes contextos nacionais (Teixeira et alii, 2004), com suas múltiplas linhas de pesquisa associadas (Brunner e Uribe, 2007:27-179) sobre, por exemplo, os fenômenos do "capitalismo acadêmico" (Slaughter e Rhoades, 2004), a aparição de novos provedores (Kinser e Levy, 2006; Middlehurst e Woodfield, 2004), a comercialização da pesquisa e a empresarialização das universidades (Clark, 2004; 1998).

Em sexto e último lugar, é necessário destacar, na evolução do campo, o crescente foco comparativo dos estudos provenientes tanto de fontes 
acadêmicas como de alguns organismos internacionais que intervêm sobre elas com sua própria produção de conhecimento, como o Banco Mundial (World Bank, 2002) e a OECD (2008). Ao se internacionalizar, o próprio campo perde em parte seu caráter especificamente local e nacional (como ocorre também com as próprias universidades), e suas perspectivas se globalizam. Ao mesmo tempo, os centros tradicionalmente dominantes do campo mantêm sua posição, mas seus interesses de pesquisa se estendem à periferia, e esta incorpora, ainda que não subordinadamente, suas próprias realidades e análises.

Surge, além disso, pelo uso de indicadores comparativos internacionais, um ramo de estudos de benchmarking com propósitos de difusão (habitualmente concebidos de maneira muito ingênua) de "boas práticas" e de "modelos de sucesso". Também se impõem - no âmbito da educação superior global - os rankings de universidades chamadas de "classe mundial" (Salmi, 2007), que, como era de se esperar, apenas refletem dentro do âmbito das instituições de conhecimento a geopolítica da distribuição dos poderes econômico, tecnológico e militar na esfera mundial (Marginson, 2006; 2004). Enfim, no caso da sociologia da educação superior, encontramo-nos diante de um campo que evoluiu por crescimento e especialização temática, por ampliação da cobertura geográfica, pela incorporação de novos assuntos e atores, por hibridação disciplinar e pela diversificação de suas orientações e modos de produção de conhecimento.

\section{AMÉRICA LATINA: UM CAMPO POUCO INSTITUCIONALIZADO}

A presença e a participação da América Latina, do Chile, em particular, nesse campo em rápida evolução, caracterizam-se por pobre contribuição, reduzido grau de institucionalização e, ainda assim, aporte a algumas perspectivas e tópicos de estudo - dependentes de seus contextos de desenvolvimento específicos e peculiares - que merecem atenção. De fato, ao medir a produção latino-americana de conhecimento no campo dos estudos da educação superior com os indicadores comumente utilizados - bibliométricos e de participação na literatura -, que periodicamente expressam o estado-da-arte do campo, seu aporte quantitativo é absolutamente marginal.

É mínimo o número de artigos oriundos da região publicados durante a última década em revistas da corrente principal (mainstream), quer dizer, registradas internacionalmente (por exemplo, nas bases de 
Thomson ISI), sendo próprias do campo ou pertencentes às perspectivas disciplinares que participam dele, em particular da sociologia da educação superior, e o número de autores com produção contínua, medidos por esse parâmetro, é ínfimo. Efetivamente, a maioria dos pesquisadores latino-americanos do campo publica seus resultados, reflexões e argumentos em revistas não indexadas, em documentos de trabalho institucionais e em livros, e só excepcionalmente em inglês ou em outro idioma. A geração mais jovem de pesquisadores latino-americanos do campo, a maioria com estudos de pós-graduação em universidades dos Estados Unidos, começa a se preocupar seriamente em publicar em revistas com registro internacional.

Algo parecido ocorre com a participação de autores latino-americanos na literatura internacional tipo estado-da-arte. Como mostra García Guadilla (2000) em relação à enciclopédia editada no começo dos anos 1990 por Clark e Neave (1992), embora as seções destinadas à análise das diferentes perspectivas disciplinares que convergem no estudo da educação superior - citadas anteriormente - contenham mais de mil referências bibliográficas, só vinte são de títulos publicados em idiomas diferentes do inglês, sendo treze em alemão, três em francês, três em russo e uma em italiano. Nenhum dos autores dessas seções é da América Latina. Algo parecido ocorre com o mais recente estudo de síntese sobre educação terciária no âmbito mundial (OECD, 2008): entre várias centenas de autores citados (publicados em inglês, com mínimas exceções), os autores latino-americanos aparecem em cerca de dez referências, menos de 3\% do total.

Em seguida, observa-se o baixo grau de institucionalização do campo na América Latina, o que vale também para o Chile. Isso se deve particularmente à inexistência de departamentos ou de centros de pesquisa com trajetória relativamente estável de produção, ainda que sejam de alcance puramente local/nacional. Deve-se também à ausência de programas de doutorado nesse campo ou de especializações temáticas enfocadas na educação superior dentro dos departamentos, escolas e institutos de sociologia.

Com exceção do México, onde alguns núcleos de pesquisa conseguiram se consolidar, na América Latina predominam pequenos grupos de pesquisadores escassamente associados ou pesquisadores isolados que se relacionam com outros, dentro de seu país, por meio de redes in- 
formais e contatos mais ou menos esporádicos, com poucas figuras que transcendem o âmbito local.

Há, além disso, em alguns países, revistas dedicadas a temas de pesquisa de campo, mas com escassa difusão a nível regional e nem sempre disponíveis na internet. A maior parte dessas revistas mais reflete e comunica as preocupações dos agentes do que expõe uma trajetória acumulativa de conhecimentos especificamente acadêmicos. Desenvolveram-se, igualmente, em diferentes conjunturas, projetos colaborativos de alcance regional, como manifesta a publicação de relatórios sobre o estado da educação superior regional (Iesalc, 2008; 2006; Cinda, 2007; García Guadilla, 1996; 1996a; Brunner et alii, 1995). Tem havido, ainda, iniciativas de colaboração com universidades europeias que culminam em publicações com participação preponderante, também nesse caso, de agentes ${ }^{3}$. Por outro lado, como mencionado, a América Latina contribuiu ao longo de décadas com algumas perspectivas e tópicos de estudo - dependentes dos contextos de desenvolvimento específicos e peculiares de sua educação superior - que merecem atenção.

Se nos limitarmos apenas às contribuições provenientes do campo da sociologia da educação superior e das perspectivas de análise mais afins (economia política e políticas públicas), é possível observar que a América Latina contribuiu, inicialmente, com conhecimento de interesse distintivo nas quatro áreas mencionadas na primeira seção deste artigo. De fato, realizaram-se diversos estudos nacionais sobre desigualdades na educação após o ensino médio, especialmente mediante análise de dados de enquetes domiciliares. Embora em sua maioria sejam basicamente descritivos e careçam, por isso mesmo, de pretensão teórica, esses estudos iluminam uma zona de problemas particularmente agudos na América Latina, por ser essa a região mais desigual do mundo do ponto de vista de distribuição de renda, ainda que não de distribuição educativa (De Ferranti et alii, 2005:141-145). De qualquer forma, esse tópico constitui foco de atenção permanente e dá lugar a um fluxo mais ou menos contínuo de publicações em diferentes países da região.

Vinculados tematicamente a esses estudos, são abordados também alguns tópicos da segunda área, que se ocupa do impacto da experiência de cursar a faculdade para os estudantes. Aqui são destacáveis, por exemplo, os estudos referentes à retenção e à deserção universitária 
dos jovens (Cinda, 2006; Donoso e Schiefelbein, 2007); a análise dos processos de seleção dos estudantes e os efeitos da seletividade das instituições (Brunner e Uribe, 2007:218-238); sua inserção no mercado de trabalho, o papel das credenciais obtidas no momento da graduação e seus efeitos sobre a mobilidade social.

A profissionalização acadêmica, como já mencionado, foi objeto de diversas e minuciosas pesquisas, particularmente no caso do México, em relação à diferenciação das instituições (Schwartzman, 2006:120-133; 1991) e às modalidades de trabalho acadêmico e suas formas de retribuição, em especial mediante o uso de esquemas de incentivo que progressivamente corroem a tradicional uniformidade das escalas salariais dos acadêmicos no setor universitário público (García de Fanelli, 2007; Bensimon e Ordorika, 2006; Krotsch, 2002:parte B).

Por último, é provavelmente na área da análise dos sistemas - embora não das instituições - como organizações que existe o maior acúmulo de estudos referentes em especial às trajetórias dos sistemas nacionais (López Segrera, Brock e Dias Sobrinho, 2008), aos efeitos de massificação da matrícula terciária, à diferenciação dos sistemas, aos papéis das universidades públicas e do setor universitário privado, às suas relações variáveis com o Estado e com a sociedade, aos modelos de financiamento de oferta e demanda $\mathrm{e}$, mais recentemente, também às consequências da instalação de regimes de certificação de qualidade (Brunner e Peña, 2008; Cinda, 2003; CNA, 2003; García Guadilla, 2002; 1996; Muñoz, 2002; Kent, 2001; Rodríguez e Casanova, 1994).

Como será visto mais adiante, foi com base nesses estudos situados na esfera dos sistemas que se desenvolveu uma literatura propriamente latino-americana no campo da sociologia da educação superior.

De fato, emerge desde cedo na região uma literatura referente à especificidade do modelo latino-americano, como mostra a análise sociológica da realidade universitária latino-americana de Scherz (1968) e publicações de autores como Ribeiro (1969), bem como as expressões mais recentes, por exemplo, de Bernasconi, que anunciam o fim desse modelo. Efetivamente, como aponta esse último autor,

[...] após a independência da América e durante todo o século XIX e a maior parte do século XX, existiu um modelo de universidade latino-americana. A consolidação das universidades privadas na segunda metade do século passado, que em sua maioria não responderam a esse 
padrão, restringiu a influência do modelo ao setor público da educação superior. Em tempos mais recentes, por questões relacionadas à economia do conhecimento, à globalização, às restrições financeiras, à perda de legitimidade e às transformações na missão, a influência do modelo sobre as universidades públicas também diminuiu, e o paradigma da universidade de pesquisa dos Estados Unidos, que foi durante muito tempo a inspiração dominante no setor privado, começou a exercer influência também sobre as universidades públicas. $O$ resultado é que, não obstante a persistência de elementos do velho paradigma em algumas partes do setor público, o modelo de universidade latino-americana se encontra hoje sobretudo na ideia da universidade de pesquisa, especialmente inspirado nas universidades norte-americanas dedicadas intensivamente à pesquisa (Bernasconi, 2008:30).

Ao longo do tempo, esse tema foi objeto de diversas interpretações. Por exemplo, apontou-se o caráter artificial dos processos de transferência institucional durante o período colonial (Schwartzman, 1992); depois, a importância que adquirem as universidades para a construção dos Estados-nações independentes (Serrano, 1994); o papel que se esperava que as universidades cumprissem nos processos de modernização das sociedades (Atcon, 1963; Shils, 1976); as resistências socioculturais que as instituições latino-americanas opunham a esses processos de modernização impostos de cima (Steger, 1974); as peculiares características da politização das universidades e os movimentos estudantis na região (Solari, 1967; 1968; Graciarena, 1984; Shils e Roberts, 2004); e as distorções dos princípios de accountability importados dos países desenvolvidos do Norte sob a forma de procedimentos de avaliação e de certificação institucionais (Brunner, 2007). Aliás, recentemente, tentou-se tipificar as diversas fases ou etapas das reformas da educação superior na América Latina (Rama, 2006).

Como consequência das peculiaridades da evolução política latinoamericana entre os anos 1960 e o início dos anos 1970, o enfoque inicial sobre as particularidades do modelo universitário latino-americano dá lugar a uma proliferação de livros e de artigos, com caráter mais marcado de polêmica ideológica e de "ensaio político", que tratam a situação e o papel da universidade latino-americana em condições de capitalismo dependente e suas potencialidades (ou obstáculos) para se unir ao processo revolucionário na região, como aparece em diversos autores (Vasconi, 1969; Reca, 1970; Ianni, 1970; Silva Michelena e Sonntag, 1970). Hoje, esse filão da literatura desapareceu quase por 
completo, sem marcar presença até mesmo na vertente crítica tratada mais adiante, na qual não se encontram rastros desses autores do passado. Sic transit gloria mundi. Durante o auge das teorias da dependência (Kay, 1989; Larrain, 1989), algumas análises sobre a "fuga de cérebros" e sobre o papel subordinado das ciências nacionais adquirem particular visibilidade e se discute ainda o papel dos intelectuais na configuração dos partidos e dos movimentos revolucionários.

Em particular, desenvolve-se durante esses anos uma literatura - também especificamente latino-americana - sobre a posição da universidade dentro das relações de poder nas sociedades latino-americanas (Graciarena et alii, 1984) e a respeito do papel político dos movimentos estudantis que, partindo das tradições da Reforma de Córdoba, de 1918 (Portantiero, 1978; Marsiske Schulte, 2004), se projetam no tempo, discutem a organização e o papel dos movimentos universitários (Solari, 1967; 1968); sua participação nas reformas dos anos 1960 (Tedesco, 1986) em conexão com o que, em certo momento, Medina Echavarría (1967:168) chamou de "universidade militante" (aquela "que se deixa invadir sem nenhum filtro pelos barulhos da rua e reproduz em seu seio, em exato microcosmos, todos os conflitos e paixões do mundo"); suas posteriores transformações dentro do quadro de massificação e de crescente privatização da educação superior na América Latina; e o radical enfraquecimento ou fragmentação - de objetivos, conteúdos e estilos - dos movimentos estudantis no início do século XXI (Rama, s/d).

Também em virtude das vicissitudes políticas da região e da emergência dos regimes autoritários depois dos golpes militares, com a subsequente intervenção e "depuração" das universidades, particularmente no Cone Sul, surge nesse campo uma corrente de literatura dedicada a entender as transformações pelas quais, nessas condições especiais, passa a educação superior. Aqui o foco de análise está na subordinação política das universidades, na repressão dos movimentos estudantis e dos centros acadêmicos, nas mudanças no governo das universidades públicas, nas novas relações que se estabelecem entre estas e os Estados nacionais, no impulso dado às instituições privadas e nos efeitos deletérios das ditaduras militares sobre o trabalho de pesquisa, particularmente nas áreas de humanidades e ciências sociais (Brunner, 1988). Naturalmente, as condições nacionais específicas marcam também a diversidade de análise e os resultados nessa parte da literatura do campo, com base nas circunstâncias próprias e peculiares de cada 
contexto em que se produzem aqueles fenômenos (Scherz, 2005; Balán, 1993; Schwartzman, 1993; Klein e Schwartzman, 1993; Brunner, 1993; Brunner e Barrios, 1987).

A questão das universidades privadas passa a ocupar também, desde esse momento, um lugar central no frágil campo latino-americano da sociologia da educação superior. De fato, é um autor norte-americano, Levy (1986), quem produz a primeira síntese de pesquisa sobre esse setor, servindo daí em diante como marco de referência para análises posteriores (Bernasconi, 2006; 2006a; 2003; 2003a). Nessa linha, abordam-se a variedade de instituições privadas que participam do mercado da educação superior, suas peculiaridades de organização e funcionamento, a construção de identidades diferenciadas e seus modelos de financiamento e de negócios. De modo paralelo, desenvolve-se uma perspectiva crítica que, sob a marca da suspeita - embora não necessariamente acompanhada de uma sólida pesquisa empírica -, realiza a crítica dos fenômenos de privatização da educação superior latinoamericana.

Em consonância com a anterior, desenvolve-se uma linha de análise também fortemente marcada pela polêmica ideológica - sobre as transformações da universidade pública latino-americana, especialmente a partir do que se chamou de "década perdida" para o crescimento da América Latina, com seus efeitos negativos sobre o gasto público em educação superior, o retraimento do apoio estatal às universidades públicas, a perda de poder aquisitivo do salário dos professores, as intermitentes oscilações do investimento em pesquisa e em desenvolvimento, e a sensação generalizada no setor público de educação de que havia começado uma nova fase de relações entre as universidades públicas e os governos (Brunner, 2005; 1994) que prejudicaria o status e o papel tradicional das primeiras.

Em especial, e quase como uma subárea, desenvolve-se na América Latina, durante as últimas duas décadas, uma vertente de literatura crítica que, partindo da crise dos sistemas públicos de educação superior e das mudanças nas relações entre as universidades estatais e os Estados nacionais, aponta os fenômenos de globalização e das políticas neoliberais como responsáveis pela privatização, pela comercialização e pelo progressivo enfraquecimento dos sistemas nacionais de educação terciária. Um dos exemplos mais fortes e acabados desse enfoque é a compilação de artigos feita por Mollis (2003). 
Em sua ramificação mais precária e menos afortunada, essa vertente extrai habitualmente sua análise do contexto externo, ou seja, das variáveis exógenas à universidade, para concluir por aproximação mais do que com base em sólida acumulação de evidência empírica - que seus efeitos estariam afetando negativamente as variáveis endógenas das instituições e dos sistemas: desde o salário docente até as formas de governo corporativo; das práticas dos professores na sala de aula à cultura dos acadêmicos; das funções de bem público das universidades a seu papel como consciência crítica da sociedade.

Normalmente esses estudos começam por identificar (em geral de maneira negativa) as tendências mundiais - caracterizadas como globalização destrutiva das economias, dualização das sociedades, aprofundamento da pobreza, perda de coesão social, defasagens digital e tecnológica emergentes, deterioração da democracia, erosão do Estado, mcdonaldização da cultura etc. - para depois examinarem o papel dos principais agentes ideológicos da globalização (habitualmente cabem nessa categoria o Banco Mundial, o Fundo Monetário Internacional (FMI), várias agências especializadas das Nações Unidas e a OCDE, como se pode observar em Rhoades, 2007:10; López Segrera e Maldonado, 2002; López Segrera, 2001) e deduzirem daí, finalmente, seus efeitos diretos e indiretos sobre a educação superior.

Esses efeitos estariam tornando a universidade "comercial" e "controlada", ou seja, heterônoma e mercantil, e aparecem sobretudo em instituições privadas e em novos provedores estrangeiros, mas também em universidades públicas baseadas na cobrança de mensalidades, com programas orientados aos clientes, vinculadas à indústria, dominadas por uma racionalidade corporativa de negócios que precarizam o trabalho acadêmico, terceirizam serviços, reduzem custos, recebem financiamentos condicionantes e são coordenadas sob um regime que se alimenta diretamente do mercado ou, indiretamente, de mecanismos de tipo mercado (Schugurensky, 2007:307).

Em síntese, embora a pesquisa latino-americana ocupe um lugar marginal dentro do campo internacional da sociologia da educação superior, alguns de seus avanços mais idiossincráticos - dependentes portanto dos contextos histórico, político-econômico e cultural dentro dos quais se desenvolve - oferecem perspectivas de análise que têm o valor de sua especificidade local e às vezes contribuem com elementos de in- 
teresse para os estudos comparativos de políticas e para a evolução dos sistemas.

Fora isso, o aporte latino-americano parece estar concentrado em uma espécie de especulação crítica sobre os fenômenos contemporâneos da universidade. Tal especulação, inspirada pelo mesmo espírito ou páthos dos anos 1960 ou 1970, busca explicar o mal-estar que existe em círculos da academia tradicional diante da transição que experimenta a educação superior da região, em direção a formas de organização mais complexas e afastadas da inspiração, e diante das coordenadas do modelo de Córdoba, que Bernasconi (2008:31) resumiu da seguinte maneira, baseado em Figueiredo-Cowen (2002) e em Schugurensky e Naidorf (2004):

1) Governo democrático, ou seja, cogoverno por parte de estudantes, professores e ex-alunos, cujos representantes seriam eleitos para integrar os conselhos deliberativos tanto na esfera da faculdade como na da universidade.

2) Orientação da missão da universidade rumo à solução dos problemas sociais, econômicos e políticos do país.

3) A instituição, na universidade, de uma função de extensão, junto com a pesquisa e com a docência, cujo propósito seria levar a universidade às massas trabalhadoras.

4) Democratização do acesso por meio da educação gratuita e da expansão das vagas.

5) Liberdade acadêmica e autonomia em relação à intervenção estatal.

6) Seleção dos professores por intermédio de concursos competitivos e públicos baseados no mérito acadêmico.

7) Pesquisa original sob responsabilidade de professores com dedicação exclusiva comprometidos com a universidade.

Atualmente nos encontraríamos, na região, diante de uma série de transições em direção à situação que Didriksson (2008) e colaboradores apresentam desta forma:

1) Das universidades públicas tradicionais que dominavam o panorama da região, passou-se à organização de um sistema de educação superior complexo, heterogêneo e segmentado socialmente, que apresenta uma realidade diferente de sua história original; de instituições de um só campus urbano, passou-se às macrouniversi- 
dades públicas nacionais com multicampus de estruturas diferenciadas e de acordo com sistema segmentado e diversificado.

2) Das escolas técnicas e vocacionais de nível médio superior, conformou-se um importante aparato de instituições politécnicas e tecnológicas de níveis médio, médio superior e superior.

3) Da existência de algumas e pouco significativas escolas privadas, passou-se a uma condição de domínio destas em muitos países, com a concentração que tem a empresa privada no acesso social e no número de suas instituições.

4) Da escassa pesquisa científica e do número reduzido de pesquisadores, conta-se agora com uma multiplicidade de laboratórios e institutos de ciência que abarcam todas as áreas do pensamento humano e de suas fronteiras, apesar de suas insuficiências.

5) De alguns milhares de estudantes que compunham a elite de profissionais, a região vive a massificação da demanda social pela educação superior.

Às mudanças mencionadas antes seria necessário acrescentar as do novo período no qual nos encontramos, tais como a comercialização e a mercantilização das escolas privadas; o impacto das novas tecnologias que redefinem os espaços de aprendizagem; o desenvolvimento de novas áreas de conhecimento de base interdisciplinar que começam a ser vistas como substitutivas das conformações curriculares tradicionais e da oferta atual de cursos de graduação; a severa contração dos recursos financeiros fornecidos pelos governos, com uma mistura de mecanismos de avaliação, rendição de contas e aparato de certificação que valorizam o desempenho de instituições, programas e pessoas; a importância que está adquirindo a internacionalização dos processos de aprendizagem; o surgimento de novas redes e associações acadêmicas; a mobilidade dos estudantes; e os novos processos de transferência e de gestão dos conhecimentos.

São esses trânsitos, enfim, que põem hoje o campo da sociologia latino-americana da educação superior diante do desafio de se renovar ou de se enfraquecer na marginalidade. Como mencionei em outro texto (Brunner, 2009), a novidade do panorama está dada agora sobretudo pela irrupção do mercado nos espaços tradicionalmente político-corporativos e burocrático-corporativos nos quais até o momento as universidades se haviam desenvolvido e consagrado seus direitos, ele- 
vando-se até a esfera do público e envolvendo-se em uma aura especial. Elas se encontram forçadas a se adaptar ao novo contexto seja porque os governos as obrigam a atuar em mercados administrados ou quase mercados para buscar sua parte da renda nacional - como ocorre especialmente na Europa Ocidental -, seja porque se encontram diretamente em "situação de mercado" (Weber, 1964:62-64), como é o caso dos Estados Unidos, do Japão, da Coreia e outros países da Ásia, da Polônia e outras sociedades da Europa Central, do Leste Europeu e de numerosos países latino-americanos.

Em ambos os casos, embora em diferentes graus e de diversas maneiras, as instituições devem competir e diversificar suas fontes de ingresso; surgem novos provedores (instituições privadas, universidades corporativas, cursos a distância, via internet); os estudantes pagam mensalidades e passam a ser clientes; os professores são contratados e deixam de ser funcionários; as funções institucionais se transformam em desempenhos e estão sujeitas a minuciosas medições; enfatiza-se a eficiência e o value for money; os modelos de negócio substituem, na prática, os planos estratégicos; a gestão se racionaliza e adota um estilo empresarial; o governo colegiado se transforma em corporativo ao passar a ser independente dos acadêmicos e a ser integrado por representantes dos stakeholders externos; os pesquisadores são estimulados a patentear e os professores, a vender docência "empacotada" às empresas; os incentivos vinculados à produtividade acadêmica substituem as escalas salariais associadas ao cargo; os currículos são revisados e sancionados em função de sua pertinência para o trabalho e avaliados por agências externas em relação à qualidade; as culturas distintivas das instituições e suas "tribos acadêmicas" começam a ser tratadas como assuntos de clima organizacional; as universidades são comparadas mediante rankings locais e classificadas geopoliticamente em nível global (eis aí a realpolitik dos prestígios institucionais); cria-se um mercado global para serviços de educação superior, e sua regulação se resolve nas rodas do GATS (Acordo Geral sobre Comércio de Serviços [General Agreement on Trade Services]), e não na sede acadêmica. Enfim, "a universidade já não é mais um lugar tranquilo para ensinar, realizar trabalho acadêmico a um ritmo pausado e contemplar o universo como ocorria nos séculos passados. Agora é um negócio potente, complexo, demandante e competitivo que requer investimentos contínuos e de grande escala" (Skilbeck, 2001). 


\section{CHILE: PRECARIEDADE DO CAMPO E PRODUÇÃO SEMIPROFISSIONAL}

No Chile, o campo da sociologia da educação superior está apenas esboçado. Do ponto de vista da organização do trabalho e da produção de conhecimentos, é composto na atualidade de três círculos:

1) Um reduzido núcleo de pesquisadores que em geral trabalham individualmente, relacionam-se frouxamente entre si, mas se orientam de modo comum pelos enfoques e conceitos provenientes do campo especializado internacional, tendendo a citar a literatura produzida por este e a publicar regularmente - em suas próprias linhas de pesquisa - dentro e fora do país. São reconhecidos pela comunidade de pares como especialistas do campo de cujas redes formam parte.

2) Um círculo intermediário composto de pesquisadores que trabalham em diversas disciplinas além da sociologia (em especial economia, história, educação/pedagogia), mas que, com mais ou menos regularidade, abordam em suas pesquisas assuntos relativos à educação superior. Publicam de preferência em revistas (indexadas ou não) de suas próprias disciplinas e não estão integrados às redes do campo especializado de estudos sobre educação superior.

3) Um círculo externo composto de agentes reflexivos que, além de pesquisar, publicam sobre diversos tópicos relacionados à educação superior e a seus aspectos institucionais, habitualmente com base em sua experiência ao longo de uma trajetória de gestão acadêmica ou de administração de instituições. Esses agentes provêm de diferentes disciplinas, incluindo medicina, engenharia, administração de negócios, psicologia e outras, e seus membros interagem com membros dos dois círculos anteriores, especialmente em conferências, cursos e seminários com agendas dedicadas à análise das políticas no âmbito do sistema e das universidades.

O tamanho do campo em seus três círculos pode ser calculado de acordo com as publicações registradas no Google Acadêmico, procedimento que permite incluir um conjunto maior de textos do que os registrados nas bases destinadas exclusivamente à contabilidade da produção em revistas científico-disciplinares indexadas (Brunner e Salazar, 2009).

Aplicado esse procedimento com critérios não muito restritivos ${ }^{4}$, o núcleo (primeiro círculo) aparece composto de 36 pesquisadores (entre 
eles, seis mulheres), dos quais nove são sociólogos e/ou possuem formação especializada no campo da educação ou da educação superior. No entanto, dos 36 pesquisadores registrados (independentemente da idade e do número de publicações com duas ou mais menções), três publicam na atualidade principalmente sobre outros níveis do sistema educacional ou sobre outros tópicos não educacionais, três aparecem registrados como editores de volumes e oito deixaram de publicar. Logo, o núcleo ativo está composto de 22 investigadores com produção individual muito variável (entre um só artigo e mais de cinquenta; apenas cinco com mais de cinco artigos) e com graus também variáveis de impacto per capita (entre duas e mais de 450 menções). Deles, nove pertencem à geração antiga (em torno de 55 anos ou mais de idade) e treze à geração jovem. Conforme os resultados da busca, os pesquisadores do núcleo ativo publicam preferencialmente sobre: o sistema e as instituições como unidades de análise (dez), a área de acesso e de seleção (quatro), tópicos relacionados à avaliação e à certificação de qualidade (três), diversos aspectos do financiamento da educação terciária (quatro) e processos docentes (um).

O círculo intermediário está integrado por 116 pesquisadores de diferentes disciplinas que, em algum momento durante os anos 1953 e 2007, publicaram um ou mais artigos (citados duas ou mais vezes), dos quais se pode estimar que onze têm produção relativamente regular no campo, a maioria deles com base na perspectiva da análise econômica da educação superior.

Por último, o círculo externo, dos agentes reflexivos, está composto de 32 profissionais (em nosso corpus) - a maioria deles da área da saúde que publicaram só um artigo registrado no Google Acadêmico, habitualmente com poucas menções. Em suma, o campo no Chile é de tamanho reduzido e apresenta adicionalmente as mesmas debilidades institucionais observadas para a região latino-americana. No entanto, possui certa tradição que começa, simultaneamente, com a institucionalização acadêmica da sociologia no Chile (Brunner, 1988), com os primeiros trabalhos de Luis Scherz, mencionados anteriormente, e logo se prolonga, de modo geracional, por meio das contribuições de pesquisadores relacionados à Corporação de Promoção Universitária (CPU), à Faculdade Latino-Americana de Ciências Sociais (Flacso), com sede no Chile, e ao Centro Interuniversitário de Desenvolvimento (Cinda). Durante os anos 1980, duas dessas instituições (CPU e Flacso) deram origem, junto com o Centro de Estudos Públicos (CEP), a um 
programa de estudos sobre assuntos da educação superior que resultou na publicação de uma coleção de livros com artigos de diversos autores (Gazmuri, 1992; Persico, 1992; Lehmann, 1990; Lemaitre, 1990; Cox, 1990), além de documentos de trabalho e de livros publicados nessa área de forma independente pela Flacso (Brunner e Flisfisch, 1983; Brunner, 1986; Brunner e Barrios, 1987; Arriagada, 1989; Brunner, 1989; Brunner, Courard e Cox, 1992) e pela CPU, em sua revista Estudios Sociales, em uma série de documentos de trabalho e em uma coleção de livros - Atria e Courard, 2000; Salas, 2000; Castro, 2000; e aqueles compilados por Maria Cecília Persico e Pablo Persico.

Também alguns organismos regionais com sede no Chile, como a Comissão Econômica para a América Latina e o Caribe (Cepal), nos quais trabalharam vários autores citados na seção anterior (por exemplo, Medina Echavarría, Graciarena e Solari), e a Oficina Regional de Educação para a América Latina e o Caribe (Orealc), da Unesco, contribuíram esporadicamente com pesquisas sobre educação superior relacionadas à economia e às sociedades da América Latina (Cepal, 1992). O mesmo ocorre, como já mencionado, com o aporte realizado à literatura pelos pesquisadores que trabalhavam dentro da escola da teoria da dependência, agrupados sobretudo no Centro de Estudos Socioeconômicos (Ceso) da Universidade do Chile.

Hoje, nosso campo apenas esboçado se vê incipientemente fortalecido por uma série de iniciativas que contam com respaldo público. Em primeiro lugar, e já desde há alguns anos, o Conselho Superior de Educação do Chile publica semestralmente a revista Calidad en la Educación, dedicada exclusivamente a temas de educação superior e que já conta com trinta números (considerando o 1o semestre/2009). O Conselho também organiza, anualmente desde 1996, um seminário internacional com o objetivo de reunir pesquisadores e agentes, e oferecer um foro para debate de assuntos de interesse para a política e para as instituições de educação superior ${ }^{5}$. Além disso, convoca anualmente um concurso de pequenos projetos de pesquisa sobre temas de educação superior aberto a estudantes de mestrado e doutorado e a pesquisadores com experiência pertencentes a universidades ou a centros de estudo.

Em seguida, os pesquisadores interessados em realizar estudos de maior alcance no campo podem apresentar projetos para o Fundo Nacional de Desenvolvimento Científico e Tecnológico (Fondecyt) em 
seus concursos regulares ou de iniciação à pesquisa. No entanto, como parte dos próprios pontos fracos do campo, durante os últimos oito anos, só vinte projetos relacionados à análise da educação superior foram aprovados nos concursos regulares ${ }^{6}$. Desses projetos, cinco são de pesquisadores do núcleo identificado anteriormente e se referem sobretudo ao sistema nacional e às instituições como unidade de análise, abordando aspectos da economia política, regulações, papel dos acadêmicos e desigualdades no acesso e na distribuição de oportunidades. Seis projetos abordam questões próprias da aprendizagem e do ensino, práticas pedagógicas e esquemas de cognição docente. Três partem da linguística e tratam sobre o discurso acadêmico no contexto da comunicação intrauniversitária. Os seis projetos restantes abordam temas específicos a partir de diversos ângulos disciplinares: o ensino de direito na universidade colonial de San Felipe; o uso de dispositivos digitais na sala de aula sob a perspectiva da engenharia informática; a violência entre casais universitários do ponto de vista da psicologia clínica; a percepção das ciências entre os habitantes de três cidades universitárias; as orientações para a ciência, para a inovação e para o civismo estudadas com base no enfoque da sociologia; e, por fim, as condições do ensino de filosofia nas universidades chilenas.

Por último, a Comissão Nacional de Ciência e Tecnologia (Conicyt), dentro de seu programa Círculos de Pesquisa em Ciências Sociais (concurso de 2007), na modalidade "inovação das políticas públicas", aprovou pela primeira vez um programa de pesquisa (de três anos) sobre políticas de educação superior, do qual participam pesquisadores das universidades Diego Portales, Alberto Hurtado, de Talca e Nacional Andrés Bello ${ }^{7}$.

Apesar de seu tamanho relativamente pequeno, suas debilidades de institucionalização e seus progressos recentes, o campo de estudos da educação superior experimenta, no Chile, tensões similares àquelas que se expressam no campo internacional. Para começar, a coexistência - dentro do mesmo espaço de produção de conhecimento - entre acadêmicos dedicados ou parcialmente dedicados à pesquisa especializada, com diferentes enfoques e modos de comunicação, e agentes reflexivos que pertencem a diferentes unidades acadêmicas ou administrativas e a diversas agências e que se expressam nas variadas linguagens profissionais próprias de seu desempenho. Embora a interação entre esses grupos enriqueça, em certas ocasiões, o debate público e as propostas de políticas, e possa contribuir para uma maior reflexão a 
respeito das práticas de gestão institucional, em outras pode prejudicar o desenvolvimento mais especializado das diversas linhas de pesquisa.

De fato, os pesquisadores trabalham em um ambiente de demandas múltiplas e entrecruzadas, tendo que responder simultaneamente a interesses especificamente disciplinares que surgem de sua inscrição nos campos local, nacional, regional e global (perguntas, tópicos de pesquisa, desenvolvimentos teóricos e de método, redes de pares) e à diversidade de interesses próprios de suas instituições, agências governamentais, fundos públicos de financiamento da pesquisa, entidades privadas, organismos internacionais e meios de comunicação. Nessas condições, devem, por isso mesmo, assumir diferentes papéis: como pesquisadores (especializados) e docentes (dentro de conformações curriculares habitualmente não especializadas, nos níveis de graduação e pós-graduação); como administradores em cargos de gestão acadêmica; como consultores locais ou internacionais; como pequenos empresários para obtenção e administração de recursos; como avaliadores de projetos e programas; como promotores de sua própria carreira profissional, mediante a publicação de artigos em revistas indexadas ou reconhecidas dentro de diversas comunidades de agentes; como assessores especializados em tarefas de planejamento e execução de políticas institucionais ou nacionais de educação superior; como comunicadores na esfera pública por meio de autoria ou de edição de livros; e, cada vez mais, por sua participação nos meios de comunicação, incluindo os meios digitais.

Essa diversidade de papéis, além de exigir árduo trabalho de conciliação, supõe também a administração de um portfólio de referências variadas para diversos clientes e partes interessadas (stakeholders) que operam como fontes de identidade e prestígio. Em consequência, o pesquisador padrão do campo, à medida que avança na carreira, deve escolher entre uma maior exposição nacional, regional ou global; entre se encaminhar preferentemente para a gestão de sua própria trajetória profissional ou atender a um leque mais ou menos amplo de demandas de diferentes clientes; entre a pesquisa regida pelos modelos da comunidade internacional de pares ou pelos interesses dos agentes locais; entre o trabalho exigente em projetos com conteúdo empírico, ou a produção de conhecimentos a partir de dados secundários, ou de síntese com base na revisão da literatura disponível; entre escalar posições dentro da torre de marfim ou penetrar também nos labirintos do po- 
der; entre dedicar seu tempo à publicação de artigos indexados (portanto, em inglês) ou usar uma parte desse recurso - o mais escasso de todos - para participar do debate público e dos meios de comunicação.

Do ponto de vista de suas orientações temáticas, é possível observar, no Chile, uma progressiva concentração de pesquisa nos tópicos que aparecem como mais relevantes para a compreensão do sistema nacional de educação terciária e para a formulação de políticas nesse setor. Em especial, citamos: a evolução do sistema e das políticas setoriais a partir dos anos 1960 (Brunner, 2009; Bernasconi e Rojas, 2004), as bases de funcionamento de sua economia política (Brunner e Uribe, 2007; Brunner et alii, 2005); o papel das universidades públicas (Samaniego, 2007; Brunner, 2005) e privadas (Bernasconi, 2006; 2006a; 2003; 2003a; Fernández, 2008); a concepção e o impacto dos esquemas de apoio aos estudantes (Larraín e Zurita, 2006; Larrañaga, 2002); o acesso e a distribuição de oportunidades no nível terciário (Espinoza e González, 2008; 2007; Schmal et alii, 2007; Donoso e Schiefelbein, 2007; Donoso e Cancino, 2007; Díaz, 2006); os procedimentos utilizados para seleção e admissão de alunos (Manzi et alii, 2006; Araujo e Moreno, 2005; Donoso, 2000); as formas de funcionamento dos sistemas de certificação de qualidade (Lemaitre, 2004; 2004a; Brunner, 2004); a inserção dos graduados do ensino terciário no mercado de trabalho (Brunner e Meller, 2004; Meller e Rappoport, 2006; Rappoport, Benavente e Meller, 2004); o desenvolvimento, a institucionalização, a produtividade e o impacto das ciências básicas (Allende et alii, 2005; Krauskopf, Krauskopf e Méndez, 2007) e sociais (Contreras, Edwards e Mizala, 2006; Brunner e Salazar, 2009) no marco da organização acadêmica das universidades e, mais recentemente, sua vinculação com a indústria e a inovação (Benavente, 2008; 2005; 2004).

Uma parte desses estudos tem servido de base ou nutrido a preparação dos diversos relatórios referentes à política desse setor encomendados pelo governo ou publicados por aqueles que ocuparam cargos de alta gestão no âmbito da educação superior (Comisión de Estudios de la Educación Superior, 1991; Allard, 2000; Arellano, 2000:cap. 5; Ministerio de Educación de Chile, 2001; Consejo Asesor Presidencial para la Educación Superior, 2008).

A discussão e a análise mais gerais sobre a posição do sistema de educação terciária nas sociedades do capitalismo global e na modernidade tardia - como em determinado momento e em condições diferentes do 
desenvolvimento capitalista fizeram, por exemplo, Medina Echavarría e, em outra direção, os autores da escola da dependência - se encontram, na atualidade, praticamente ausentes de nosso campo, com poucas exceções (Peña, 2008; Brunner, 2008; Thayer, 1996). Contudo, uma reflexão mais persistente nesse sentido serviria para dar um marco maior e teoricamente mais consistente à produção nacional de conhecimento no setor, apelando precisamente para a sociologia sobre as transformações da época. De fato, no campo internacional, vários autores já iniciaram esse percurso, como pode ser observado em Weiler (2006), Derrida (2004), Habermas (1989), em vários artigos reunidos em Smith e Webster (1997) e em Lyotard (1984).

Alguns desses esforços intelectuais poderiam ser classificados, segundo os termos de Clark citados anteriormente, como cogitações inseridas em amplos esquemas e expressas em linguagem pomposa que apontam alto demais, tratam de explicar demais e são publicadas em textos que circulam exclusivamente em um circuito de conhecimento esotérico. Que seja! Ao mesmo tempo, na ausência desse tipo de exercício intelectual, o campo se arrisca - como ocorre hoje no Chile - a permanecer encurralado entre os interesses variáveis e dispersos dos agentes e a incessante luta dos pesquisadores mais especializados para serem reconhecidos por pesquisas descritivas e de conteúdo puramente local.

(Recebido para publicação em fevereiro de 2009)

(Versão definitiva em maio de 2009) 
Sociologia da Educação Superior nos Contextos Internacional, Regional e Local

\section{NOTAS}

1. Ver o site The International Comparative Higher Education Finance and Accessibility Project (ICHEFAP). Disponível em http://www.gse.buffalo.edu/org/ IntHigherEdFinance. Acessado em janeiro de 2009.

2. Ver as publicações do Centro disponíveis em http://www.utwente.nl/cheps / publications/complete_list/english. Acessado em janeiro de 2009.

3. Trata-se basicamente de dois projetos: o Projeto Alfa Tuning sobre estruturas curriculares na América Latina (Beneitone et alii, 2007) e o Projeto Proflex (Profissional Flexível na Sociedade de Conhecimento). Disponível em http: / /www.upv.es / miw / infoweb/ceges/ info/6210722005c.html. Acessado em janeiro de 2009.

4. Mediante busca no Google Acadêmico realizada em 13 de setembro de 2008, usando o programa Publish or Perish para os termos vinculados "educação" + "superior" + "Chile", sem limite de ano de publicação, foram identificados 258 papers com duas menções ou mais, publicados por 184 autores de nacionalidade chilena no total. $\mathrm{O}$ texto mais antigo é de 1935 (de A. Labarca); houve sete textos distribuídos entre 1953 e 1980, o restante foi publicado após 1980 e até 2007. Há 1.750 menções para o total do corpus, sem eliminar as automenções. O índice $\mathrm{H}$ do corpus em conjunto é 18; quer dizer, há 18 artigos com número de menções superior a 18 (que reúnem $36 \%$ do total de menções). Esta é só uma tentativa inicial de dimensionar quantitativamente o campo. É provável que, em função dos termos de busca utilizados, alguns autores, artigos e menções (embora não em número significativo) fiquem fora da estimativa. Por outra parte, uma revisão mais exaustiva poderia oferecer ajustes marginais ao número de autores, papers e menções ao identificar duplicações não detectadas nessa análise.

5. Os trabalhos apresentados durante esses seminários são publicados na série Seminários Internacionais, do Conselho Superior de Educação. Estão disponíveis em http: / / www.cse.cl/public/Secciones/seccionpublicaciones / publicaciones_ seminario_internacional.aspx.

6. Cifra obtida por meio de busca realizada nas bases de dados de projetos do Fondecyt, gentilmente realizada por seu pessoal, a partir dos termos "educação superior", "universidades" e "acadêmico".

7. O site do programa está disponível em http://www.cpce.cl/website/ index3.php? id_contenido $=78 \&$ id_seccion $=30$. 


\section{REFERÊNCIAS BIBLIOGRÁFICAS}

ALLARD, Raúl. (2000), "Políticas Públicas en Educación Superior en Chile: Contexto, Programas y Proyección”. Revista de la Educación Superior Chilena, no 1, pp. 69-83.

ALLENDE, Jorge E. et alii (eds.). (2005), Análisis y Proyecciones de la Ciencia Chilena 2005. Santiago de Chile, Academia Chilena de Ciencias/Consejo de Sociedades Científicas de Chile/Programa Bicentenario de Ciencia y Tecnología/Conicyt.

ALTBACH, Philip G. (ed.). (1996), The International Academic Profession. Portraits of Fourteen Countries. Princeton, The Carnegie Foundation for the Advancement of Teaching.

. (2002), The Decline of the Guru: The Academic Profession in Developing and MiddleIncome Countries. Chesnut Hill, Boston College Center for International Higher Education.

ÁLVAREZ, Germán. (2004), Modelos Académicos de Ciencias Sociales y Legitimación Científica en México. Un Estudio Comparativo de Tres Casos. México, Anuies.

ANTONIO, Anthony L. e MUÑIZ, Marcela M. (2007), "The Sociology of Diversity", in P. J. Gumport (ed.), Sociology of Higher Education. Contributions and their Context. Baltimore, Johns Hopkins, pp. 266-294.

ARAUJO, Kathya e MORENO, Claudia. (2005), “Nudos Críticos para la Igualdad. Género y Educación Superior en Chile". Documento de Trabajo no3, Universidad Academia de Humanismo Cristiano, Programa de Estudios de Género y Sociedad (Progénero). Disponível em http://www.progenero.cl/saf/revista/uploaded/nudos $\% 20 \mathrm{cr} \%$ C3\%ADticos.pdf. Acessado em janeiro de 2009.

ARELLANO, José Pablo. (2000), Reforma Educacional. Prioridad que se Consolida. Santiago de Chile, Los Andes.

ARRIAGADA, Patricio. (1989), Financiamiento de la Educación Superior en Chile, 1960-1988. Santiago de Chile, Flacso.

ATCON, Rudolph. (1963), “La Universidad Latinoamericana”. Eco, Revista de la Cultura de Occidente, vol. 7, no 37-39, pp. 4-169.

ATRIA, Raúl e COURARD, Hernán (eds.). (2000), Participación, Gestión y Gobierno en las Universidades Estatales. Santiago de Chile, CPU.

BALÁN, Jorge. (1993), “Governance and Finance of National Universities in Argentina: Current Proposals for Change". Higher Education, vol. 25, no 1, pp. 45-59.

BASTEDO, Michael N. (2007), "Sociological Frameworks for Higher Education Policy Research", in P. J. Gumport (ed.), Sociology of Higher Education. Contributions and their Context. Baltimore, Johns Hopkins, pp. 295-316.

BECHER, Tony. (2001), Tribus y Territorios Académicos. La Indagación Intelectual y las Culturas de las Disciplinas. Barcelona, Gedisa.

BENAVENTE, José Miguel. (2004), “Empresario Chileno durante los Noventa: ¿A Self-Made Man?". Economía y Administración, no 148, pp. 4-14.

. (2005), “Investigación y Desarrollo, Innovación y Productividad: Un Análisis Econométrico a Nivel de la Firma". Estudios de Economía, vol. 32, no 1, pp. 39-67. 
(2008), “Financiamiento de la Innovación", in J. J. Brunner e C. Peña (eds.), Reforma de la Educación Superior. Aportes para el Debate. Santiago de Chile, Diego Portales, pp. 237-263.

BENEITONE, Pablo et alii. (eds.). (2007), Tuning América Latina. Reflexiones y Perspectivas de la Educación Superior en América Latina. Bilbao, Universidad de Deusto/Universidad de Groningen.

BENSIMON, Estela Mara e ORDORIKA, Imanol. (2006), "Mexico's Estímulos: Faculty Compensation Based on Piecework", in R. A. Rhoads e C. A. Torres (eds.) The University, State, and Market. The Political Economy of Globalization in the Americas. Stanford, Stanford University Press, pp. 250-274.

BERNASCONI, Andrés. (2003), Organizational Diversity in Chilean Higher Education: Faculty Regimes in Private and Public Universities. Tese de doutorado, Boston University.

. (2003a), "Private Higher Education with an Academic Focus: Chile's New Exceptionalism". International Higher Education, no 32.

. (2006), "Does the Affiliation of Universities to External Organizations Foster Diversity in Private Higher Education? Chile in Comparative Perspective". Higher Education, vol. 52, no 2, pp. 303-342.

. (2006a), "Private Universities" Institutional Affiliations as Sources of Diversification in Chilean Higher Education. School of Law, Universidad de Talca, pp. 1-54. Manuscrito.

. (2008), "Is There a Latin American Model of the University?". Comparative Education Review, vol. 52, no 1, pp. 27-52. Disponível em http://mt.educarchile.cl/ mt/jjbrunner/archives/Latin_Am_Model_U.pdf. Acessado em janeiro de 2009.

BERNASCONI, Andrés e ROJAS, Fernando. (2004), Informe sobre la Educación Superior en Chile: 1980-2003. Santiago de Chile, Editorial Universitaria.

BOURDIEU, Pierre. (1989), La Noblesse d'État. Grandes Ecoles et Esprit de Corps. Paris, Minuit.

e PASSERON, Jean-Claude. (1964), Les Héritiers. Les Étudiants et la Culture. Paris, Minuit.

BRENNAN, John e TEICHLER, Ulrich. (2008), "The Future of Higher Education and of Higher Education Research". Higher Education, vol. 56, no 3, pp. 259-264.

BRUNNER, José Joaquín. (1986), Informe sobre la Educación Superior en Chile. Santiago de Chile, Flacso.

. (1988), El Caso de la Sociología en Chile. Formación de una Disciplina. Santiago de Chile, Flacso.

. (1989), Recursos Humanos para la Investigación en América Latina. Santiago de Chile, Flacso.

. (1993), “Chile's Higher Education: Between Market and State". Higher Education, vol. 25, no 1, pp. 35-43. 
. (1994), "Estado y Educación Superior en América Latina", in G. Neave e F. Van Vught (eds.), Prometeo Encadenado. Estado y Educación Superior en Europa. Barcelona, Gedisa, pp. 11-42.

. (2004), "Políticas y Mercados de Educación Superior: Necesidades de Información", in J. J. Brunner e P. Meller (eds.), Oferta y Demanda de Profesionales y Técnicos en Chile. Santiago de Chile, Ril Editores, pp. 19-85.

. (2005), "Transformaciones de la Universidad Pública". Revista de Sociología, no 19, pp. 31-49. Disponível em http:/ / mt.educarchile.cl/MT/jjbrunner/archives/2005/ 09/transformacione.html. Acessado em janeiro de 2009.

. (2007), "Dr. Prometheus Visits Latin America", in J. Enders e F. Van Vught (eds.), Towards a Cartography of Higher Education Policy Change. A Festschrift in Honour of Guy Neave. Enschede, The Netherlands, Center for Higher Education Policy Studies, pp. 265-271.

. (2007a), Universidad y Sociedad en América Latina (2a ed.). México, Xalapa, Veracruz, Biblioteca Digital de Investigación Educativa/Instituto de Investigaciones en Educación de la Universidad Veracruzana. Disponível em http://www.uv.mx/iie/ bdie/Brunner/brunner_universidad_sociedad.pdf. Acessado em janeiro de 2009.

. (2008), “El Poder Intelectual de la Universidad entre los Intereses Corporativos y las Condiciones de Mercado". Disponível em http:/ / mt.educarchile.cl/mt/jjbrunner/ archives/Poder\%20Intelectual_DEF050908.pdf. Acessado em janeiro de 2009.

. (2009), Educación Superior en Chile: Instituciones, Mercados y Políticas Gubernamentales, 1967-2007. Santiago de Chile, Ediciones Universidad Diego Portales. Disponível em http: / /openaccess.leidenuniv.nl/handle/1887/9735/items-by-author? author $=$ Brunner + Ried $\% 2 C+\mathrm{Jos} \% \mathrm{C} 3 \% \mathrm{~A} 9+\mathrm{Joaqu} \% \mathrm{C} 3 \% \mathrm{ADn}$. Acessado em janeiro de 2009.

e BARRIOS, Alicia. (1987), Inquisición, Mercado y Filantropía. Ciencias Sociales y Autoritarismo en Argentina, Brasil, Chile y Uruguay. Santiago de Chile, Flacso.

BRUNNER, José Joaquín e FLISFISCH, Angel. (1983), Los Intelectuales y las Instituciones de la Cultura. Santiago de Chile, Flacso.

BRUNNER, José Joaquín e MELLER, Patricio (eds.). (2004), Oferta y Demanda de Profesionales y Técnicos en Chile. Santiago de Chile, Ril Editores.

BRUNNER, José Joaquín e PEÑA, Carlos (eds.). (2008), La Reforma al Sistema de Educación Superior: Claves para el Debate. Santiago de Chile, Diego Portales.

BRUNNER, José Joaquín e SALAZAR, Felipe. (2009), “La Investigación Educacional en Chile: Una Aproximación Bibliométrica no Convencional". Documento de Trabajo no 1. Santiago de Chile, Centro de Políticas Comparadas de Educación (CPCE)/Universidad Diego Portales, pp.1-61. Disponível em http:/ / www.cpce.cl/es/component/ attachments/pluginemail/article/29/tmpl/component?plugin=emailattachment \&attachmentid=8\&show_captcha=0. Acessado em janeiro de 2009.

BRUNNER, José Joaquín e URIBE, Daniel. (2007), Mercados Universitarios. El Nuevo Escenario de la Educación Superior. Santiago de Chile, Diego Portales.

BRUNNER, José Joaquín et alii. (2005), Guiar el Mercado. Informe sobre la Educación Superior en Chile. Santiago de Chile, Universidad Adolfo Ibáñez. Disponível em 


\section{Sociologia da Educação Superior nos Contextos Internacional, Regional e Local}

http: / / mt.educarchile.cl/mt/jjbrunner/archives/2005/08/nuevo_libro.html. Acessado em janeiro de 2009 .

BRUNNER, José Joaquín (coord.) et alii. (1995), Educación Superior en América Latina: Una Agenda para el Año 2000. Bogotá, Universidad Nacional de Colombia.

BRUNNER, José Joaquín, COURARD, Hernán e COX, Cristián. (1992), Estado, Mercado y Conocimiento: Políticas y Resultados en la Educación Superior Chilena 1960-1990. Santiago de Chile, Flacso.

CAPLOW, Theodore e MCGEE, Reece. (1958), The Academic Marketplace. New York, Basic Books.

CASTRO, Julio. (2000), Análisis Comparativo del Financiamiento a la Educación Superior: Universidades Estatales y Universidades Privadas con Aportes. 1981-1989 y 1990-1999. Santiago de Chile, CPU.

CEPAL (Comissão Econômica para a América Latina e o Caribe). (1992), Educación y Conocimiento: Eje de la Transformación Productiva con Equidad. Santiago de Chile, Cepal.

CINDA (Centro Interuniversitário de Desenvolvimento). (2003), Políticas Públicas: Demandas Sociales y Gestión del Conocimiento. Santiago de Chile, Cinda.

(2006), Repitencia y Deserción Universitaria en América Latina. Santiago de Chile, Cinda.

(2007), Educación Superior en Iberoamérica: Informe 2007. Santiago de Chile, Cinda.

CLARK, Burton R. (1973), “Development of the Sociology of Higher Education”. Sociology of Education, vol. 46, pp. 2-14.

. (1977), Academic Power in Italy. Bureaucracy and Oligarchy in a National University System. Chicago, University of Chicago Press.

(1983), The Higher Education System. Academic Organization in Cross-National Perspective. Berkeley, University of California Press.

. (1998), Creating Entrepreneurial Universities. Organizational Pathways of Transformation. Oxford, IAU/Pergamon.

. (2004), Sustaining Change in Universities. Maidenhead, England, Open University Press.

(2007), "A Note on Pursuing Things that Work", in P. J. Gumport (ed.), Sociology of Higher Education. Contributions and their Context. Baltimore, Johns Hopkins, pp. 319-324.

CLARK, Burton R. e NEAVE, Guy (eds.). (1992), The Encyclopedia of Higher Education. Oxford, Pergamon.

CNA (Conselho Nacional de Acreditação). (2003), Educación Superior, Calidad y Acreditación. Bogotá, CNA (vols. I, II e III).

COMISIÓN DE ESTUDIOS DE LA EDUCACIÓN SUPERIOR. (1991), Una Política para el Desarrollo de la Educación Superior en la Década de los Noventa. Santiago de Chile, Comisión de Estudios de la Educación Superior.

CONSEJO ASESOR PRESIDENCIAL PARA LA EDUCACIÓN SUPERIOR. (2008), Los Desafíos de la Educación Superior Chilena. Informe del Consejo Asesor Presidencial 
para la Educación Superior, pp. 1-484. Disponível em http://www.ubiobio. cl/web/descargas/InformeCAPfinal.pdf. Acessado em janeiro de 2009.

CONTRERAS, Claudia, EDWARDS, Gonzalo e MIZALA, Alejandra. (2006), “La Productividad Científica de Economía y Administración en Chile: Un Análisis Comparativo". Cuadernos de Economía (Latin American Journal of Economics), no 128, pp. 331-354.

COX, Cristián (ed.). (1990), Formas de Gobierno en la Educación Superior. Nuevas Perspectivas. Santiago de Chile, Foro de la Educación Superior/Flacso.

DEEM, Rosemary. (2001), “Globalisation, New Managerialism, Academic Capitalism and Entrepreneurialism in Universities: Is the Local Dimension still Important?". Comparative Education, vol. 37, no 1, pp. 7-20.

. (2001a), “Managing Contemporary UK Universities - Manager-Academics and New Managerialism". Academia Leadership. The Online Journal, vol. 1, no 3. Disponível em http://www.academicleadership.org/emprical_research/Managing_Contemporary_ UK_Universities_Manager-academics_and_New_Managerialism.shtml. Acessado em janeiro de 2009.

. (2004), "The Knowledge Worker, the Manager-Academic and the Contemporary UK University: New and Old Forms of Public Management?". Financial Accountability and Management, vol. 20, no 2, pp. 107-128.

DE FERRANTI, David et alii. (2005), Desigualdad en América Latina. ¿Rompiendo con la Historia? Bogotá, Banco Mundial/Alfaomega.

DERRIDA, Jacques. (2004), Eyes of the University: Right to Philosophy 2. Stanford, Stanford University Press.

DÍAZ, Pamela. (2006), Caminos para la Inclusión en la Educación Superior en Chile. Santiago de Chile, Fundación Equitas.

DIDRIKSSON, Axel. (2008), “Contexto Global y Regional de la Educación Superior en América Latina y el Caribe", in Iesalc, Tendencias de la Educación Superior en América Latina. Disponível em http://www.iesalc.unesco.org.ve/index.php?option=com_ content\&view $=$ article $\& i d=2 \% 3$ Atendencias \&catid $=3 \% 3$ Acontenido\&Itemid $=14 \&$ lang=es. Acessado em janeiro de 2009 .

DONOSO, Sebastián. (2000), “Del Éxito en la Enseñanza Media al Fracaso en la Universidad. Análisis del Racional Articulador del Sistema de Selección de Alumnos". Estudios Sociales, vol. 104, pp. 143-184.

e CANCINO, Víctor. (2007), “Caracterización Socioeconómica de los Estudiantes de Educación Superior". Calidad en la Educación, no 26, pp. 205-244.

DONOSO, Sebastián e SCHIEFELBEIN, Ernesto. (2007), “Análisis de los Modelos Explicativos de Retención de Estudiantes en la Universidad: Una Visión desde la Desigualdad Social". Estudios Pedagógicos, vol. 33, no 1, pp. 7-27.

ESPINOZA, Óscar e GONZÁLEZ, Luis Eduardo. (2007), “Perfil Socioeconómico del Estudiantado que Accede a la Educación Superior en Chile (1990-2003)". Estudios Pedagógicos, vol. 33, no 2, pp. 45-57.

. (2008), “Equidad y Acceso a la Educación superior en Chile (1990-2003)”, in J. J. Brunner e C. Peña (eds.), Reforma de la Educación Superior. Aportes para el Debate. Santiago de Chile, Diego Portales. 
FERNÁNDEZ, Enrique. (2008), “Perspectivas de Futuro de las Universidades Privadas Fundadas con Posterioridad a 1980", in J. J. Brunner e C. Peña (eds.), Reforma de la Educación Superior. Aportes para el Debate. Santiago de Chile, Diego Portales.

FIGUEIREDO-COWEN, Maria de. (2002), "Latin American Universities, Academic Freedom and Autonomy: A Long-Term Myth?". Comparative Education, vol. 38, no 4, pp. 471-484.

GARCÍA DE FANELLI, Ana. (2007), “La Reforma Universitaria Impulsada Vía el Financiamiento: Alcances y Limitaciones de las Políticas de Asignación". Espacio Abierto, Asociación Venezolana de Sociología, ano/vol. 16, no 001, pp. 7-29.

GARCÍA GUADILLA, Carmen. (1996), Conocimiento, Educación Superior y Sociedad en América Latina. Caracas, Cendes/Nueva Sociedad.

. (1996a), Situación y Principales Dinámicas de Transformación de la Educación Superior en América Latina. Caracas, Cresalc/Unesco.

(2000), "Investigación y Toma de Decisiones en Educación Superior: Una Interacción a Constituir". Nueva Sociedad, no 165, pp. 96-108. Disponível em http:// www.nuso.org/upload/articulos/2828_1.pdf. Acessado em janeiro de 2009.

. (2002), Tensiones y Transiciones. Educación Superior Latinoamericana en los Albores del Tercer Milenio. Caracas, Cendes/Nueva Sociedad.

GAZMURI, Pedro (ed.). (1992), Educación Superior en Chile. Los Programas de Postgrado yel Desarrollo Científico. Santiago de Chile, Foro de la Educación Superior/Flacso.

GIL ANTÓN, Manuel et alii. (1994), Los Rasgos de la Diversidad. Un Estudios sobre los Académicos Mexicanos. México, Universidad Autónoma Metropolitana, Azc./Unison/Piies.

GRACIARENA, Jorge. (1984), “Universidad, Inteligencia e Ideología. En Torno a Algunas Ideas de José Medina Echavarría”, in J. Graciarena et alii, Universidad y Desarrollo en América Latina y el Caribe. Caracas, Unesco/Cresalc, pp. 9-28. Disponível em http://unesdoc.unesco.org/images/0015/001520/152001so.pdf. Acessado em janeiro de 2009.

et alii. (1984), Universidad y Desarrollo en América Latina y el Caribe. Caracas, Unesco/Cresalc. Disponível em http://unesdoc.unesco.org/images/0015/ 001520/152001so.pdf. Acessado em janeiro de 2009.

GREDIAGA, Rocío, RODRÍGUEZ, José Raúl e GONZÁLEZ, Laura Elena. (2004), Políticas Públicas y Cambios en la Profesión Académica en México en la Última Década. México, Anuies.

GUMPORT, Patricia J. (ed.). (2007), “Reflections on a Hybrid Field: Growth and Prospects for the Sociology of Higher Education", in P. J. Gumport (ed.), Sociology of Higher Education. Contributions and their Context. Baltimore, Johns Hopkins, pp. 325-361.

. (2007a), Sociology of Higher Education. Contributions and their Context. Baltimore, Johns Hopkins.

HABERMAS, Jürgen. (1989), "The Idea of the University: Learning Processes", in The New Conservatism. Cultural Criticism and the Historians' Debate. Cambridge, MIT, pp. 100-127. 
HALSEY, Albert H. (1995), Decline of Donnish Dominion. The British Academic Professions in the Twentieth Century. New York, Oxford University Press.

HEARN, James C. (2007), "Sociological Studies of Academic Departments", in P. J. Gumport (ed.), Sociology of Higher Education. Contributions and their Context. Baltimore, Johns Hopkins, pp. 222-265.

HURTADO, Sylvia. (2007), "The Study of College Impact", in P. J. Gumport (ed.), Sociology of Higher Education. Contributions and their Context. Baltimore, Johns Hopkins, pp. 94-112.

IANNI, Octavio. (1970), Imperialismo y Cultura de la Violencia en América Latina. México, Siglo XXI.

IESALC (Instituto Internacional de la Unesco para la Educación Superior en América Latina y el Caribe). (2006), Informe sobre la Educación Superior en América Latina y el Caribe. 2000-2005. La Metamorfosis de la Educación Superior. Caracas, Iesalc.

(2008), Tendencias de la Educación Superior en América Latina. Disponível em http: / / www.iesalc.unesco.org.ve/index.php?option=com_content\&view=article $\& \mathrm{id}=2 \% 3$ Atendencias\&catid $=3 \% 3$ Acontenido\&Itemid=14\&lang=es. Acessado em janeiro de 2009.

JOHNSTONE, Bruce. (2006), Financing Higher Education. Cost-Sharing in International Perspective. Buffalo, NY, University of Buffalo/Ichefap.

KAY, Cristóbal. (1989), Latin American Theories of Development and Underdevelopment. London/New York, Routledge.

KENT, Rollin (ed.). (2001), Experiencias de Reformas en la Educación Superior en América Latina. Los Años 90. México, Plaza y Valdés.

KINSER, Kevin e LEVY, Daniel C. (2006), “For-Profit Higher Education: U.S. Tendencies, International Echoes", in J. J. F. Forest e P. G. Altbach (eds.), International Handbook of Higher Education. Dordrecht, The Netherlands, Springer, pp. 107-119.

KLEIN, Lúcia e SCHWARTZMAN, Simon. (1993), “Higher Education in Brazil: 1970-1990". Higher Education, vol. 25, no 1, pp. 21-34.

KOGAN, Maurice. (2000), "Higher Education Research in Europe", in OECD (ed.), Knowledge Management in the Learning Society. Paris, OECD, pp. 193-209.

KRAUSKOPF, Manuel, KRAUSKOPF, Erwin e MÉNDEZ, Bernardita. (2007), “Low Awareness of the Link between Science and Innovation Affects Public Policies in Developing Countries: The Chilean Case". Scientometrics, vol. 72, no 1, pp. 93-103.

KROTSCH, Pedro (ed.). (2002), La Universidad Cautiva. Legados, Marcas y Horizontes. La Plata, Buenos Aires, Al Margen.

LARRAIN, Jorge. (1989), Theories of Development. Capitalism, Colonialism and Dependency. London, Polity.

LARRAÍN, Guillermo e ZURITA, Salvador. (2006), El Nuevo Sistema Chileno de Préstamos Estudiantiles. Documento de Trabajo no 48, Universidad Adolfo Ibáñez, Santiago de Chile, pp. 1-32. Disponível em http:/ / www.clarrain.cl/estudios/estudiantil_es. pdf. Acessado em janeiro de 2009. 
LARRAÑAGA, Osvaldo. (2002), Elementos para una Reforma del Sistema de Crédito Estudiantil en Chile. Documento de Trabajo no 189, pp. 1-27. Facultad de Ciencias Económicas y Administrativas, Universidad de Chile. Disponível em http: / / econ.uchile. cl/public/Archivos/pub/43016dc1-e379-4d3e-9bec-5a8f62df2f62.pdf. Acessado em janeiro de 2009.

LEHMANN, Carla (org.). (1990), Financiamiento de la Educación Superior. Antecedentes y Desafíos. Santiago de Chile, Foro de la Educación Superior/Flacso.

LEMAITRE, María José. (2004), “Development of External Quality Assurance Schemes: An Answer to the Challenges of Higher Education Evolution". Quality in Higher Education, vol. 10, no 2, pp. 89-99.

. (2004a), “Mecanismos de Aseguramiento de la Calidad: Respuesta a los Desafíos del Cambio en la Educación". Calidad en la Educación, no 21, pp. 87-106.

LEMAITRE, María José (ed.). (1990), La Educación Superior en Chile. Un Sistema en Transición. Santiago de Chile, Foro de la Educación Superior/Flacso.

LEVY, Daniel C. (1986), Higher Education and the State in Latin America. Private Challenges to Public Dominance. Chicago/London, University of Chicago Press.

LÓPEZ SEGRERA, Francisco. (2001), Globalización y Educación Superior en América Latina y el Caribe. Caracas, Iesalc.

e MALDONADO, Alma. (2002), Educación Superior Latinoamericana y Organismos Internacionales. Un Análisis Crítico. Cali, Universidad de San Buenaventura.

LÓPEZ SEGRERA, Francisco, BROCK, Colin e DIAS SOBRINHO, José (eds.). (2008), “La Educación Superior en América Latina y el Caribe 2008 (Principales Tendencias y Desafíos)". Revista Avaliação, vol. 13, no 2.

LYOTARD, Jean-Françoise. (1984), The Postmodern Condition. A Report on Knowledge. Minnesota, University of Minnesota Press.

MANZI, Jorge et alii. (2006), Estudio acerca de la Validez Predictiva de los Factores de Selección a las Universidades del Consejo de Rectores. Santiago de Chile, Comité Técnico Asesor del Consejo de Rectores de las Universidades Chilenas, pp. 1-86. Disponível em http://www.cedus.cl/files/Estudio_de_Validez_Predictiva_ 2003-2006.pdf. Acessado em janeiro de 2009.

MARGINSON, Simon. (2004), "National and Global Competition in Higher Education". The Australian Educational Researcher, vol. 31, no 2, pp. 1-28. Disponível em http:/ / www. aare.edu.au/aer/online/40020b.pdf. Acessado em janeiro de 2009.

. (2006), "Dynamics of National and Global Competition in Higher Education". Higher Education, vol. 52, pp. 1-39. Disponível em http:/ / www.education. monash.edu. $\mathrm{au} /$ centres/mcrie/docs/hed-2006-national-and-global-competition.pdf. Acessado em janeiro de 2009.

e VAN DER WENDE, Marijk. (2006), Globalisation and Higher Education. Manuscrito. Disponível em http:/ / www.oecd.org/dataoecd/20/4/37552729.pdf. Acessado em janeiro de 2009.

MARSISKE SCHULTE, Renate. (2004), “Historia de la Autonomía Universitaria en América Latina". Perfiles Educativos, vol. 26, o 105-106. 
MCDONOUGH, Patricia M. e FANN, Amy J. (2007), "The Stdudy of Inequality”, in P. J. Gumport (ed.), Sociology of Higher Education. Contributions and their Context. Baltimore, Johns Hopkins, pp. 53-93.

MEDINAECHAVARRÍA, José. (1967), Filosofía, Educación y Desarrollo. México, Siglo XXI.

MELLER, Patricio e RAPPOPORT, David. (2006), “Son Siempre las Universidades la Mejor Opción para un Título Profesional? Evidencia Chilena". Documentos de Trabajo no 389, Banco Central de Chile, pp. 1-36. Disponível em http://www.bcentral. cl/eng/studies/working-papers/pdf/dtbc389.pdf. Acessado em janeiro de 2009.

MEYER, John W. et alii. (2007), "Higher Education as an Education”, in P. J. Gumport (ed.), Sociology of Higher Education. Contributions and their Context. Baltimore, Johns Hopkins, pp. 187-221.

MIDDLEHURST, Robin e WOODFIELD, Steve. (2004), The Role of Transnational, Private, and For-Profit Provision in Meeting Global Demand for Tertiary Education: Mapping, Regulation and Impact. Disponível em http:/ / portal.unesco.org/education / fr / files/31948/10880658943INF6ETransnational_Summary_Report. pdf/INF6ETransnational\%2BSummary\%2BReport.pdf. Acessado em janeiro de 2009.

MINISTERIO DE EDUCACIÓN DE CHILE. (2001), Foro de la Educación Superior, Comisión I, Comisión II, Comisión III. Santiago de Chile, Ministerio de Educación.

MOLLIS, Marcela. (1995), “En Busca de Respuestas a la Crisis Universitaria: Historia y Cultura". Perfiles Educativos, no 69, pp. 1-10.

MOLLIS, Marcela (ed.). (2003), Las Universidades en América Latina: ¿Reformadas o Alteradas? La Cosmética del Poder Financiero. Buenos Aires, Clacso.

MUÑOZ, Humberto (org.). (2002), Universidad: Política y Cambio Institucional. México, Centro de Estudios sobre la Universidad.

NOWOTNY, Helga, SCOTT, Peter e GIBBONS, Michael. (2001), Re-Thinking Science. Knowledge and the Public in an Age of Uncertainty. Cambridge/Oxford/Malden, Polity/Blackwell.

OECD (Organisation for Economic Co-Operation and Development). (2008), Tertiary Education for the Knowledge Society. OECD Thematic Review of Tertiary Education. Paris, OECD. Disponível em http://oecd-conference-teks.iscte.pt/ documents.html.

PEÑA, Carlos. (2008), “¿Obsolescencia de la Universidad Moderna? Del Conflicto de las Facultades al Capitalismo Académico", in J. J. Brunner e C. Peña (eds.), Reforma de la Educación Superior. Aportes para el Debate. Santiago de Chile, Diego Portales, pp. $23-45$.

PERSICO, Pablo (ed.). (1992), Educación Superior Chilena: Gestión y Administración Institucional. Santiago de Chile, Foro de la Educación Superior/Flacso.

PETERSON, Marvin W. (2007), "The Study of Colleges and Universities as Organizations", in P. J. Gumport (ed.), Sociology of Higher Education. Contributions and their Context. Baltimore, Johns Hopkins, pp. 147-184.

PORTANTIERO, Juan Carlos. (1978), Estudiantes y Política en América Latina. México, Siglo XXI. 
RAMA, Claudio. (2006), “La Tercera Reforma de la Educación Superior en América Latina y el Caribe: Masificación, Regulación e Internacionalización", in Iesalc, Informe sobre la Educación Superior en América Latina y el Caribe: 2000-2005. La Metamorfosis de la Educación Superior. Caracas, Instituto Internacional de la Unesco para la Educación Superior en América Latina y el Caribe, pp. 11-18.

(s/d), "El Movimiento Estudiantil del Siglo XXI". Disponível em http:/ / www.claudiorama.name/archivos / publicaciones/821ae97962bf3101baefc 26ce0acdc7f.pdf. Acessado em janeiro de 2009.

RAPPOPORT, David, BENAVENTE, José Miguel e MELLER, Patricio. (2004), “Rankings de Universidades Chilenas según los Ingresos de sus Titulados". Documentos de Trabajo no 306, Banco Central de Chile, pp. 1-42. Disponível em http:/ / www.bcentral. cl/estudios/documentos-trabajo/pdf/dtbc306.pdf. Acessado em janeiro de 2009.

RECA, Inés. (1970), “El Movimiento Estudiantil y el Proceso de Reforma de la Universidad de Chile". Revista Mexicana de Sociología, vol. 32, no 4, pp. 893-947.

RHOADES, Gary. (2007), "The Study of the Academic Profession”, in P. J. Gumport (ed.), Sociology of Higher Education. Contributions and their Context. Baltimore, Johns Hopkins, pp. 113-146.

RIBEIRO, Darcy. (1969), A Universidade Necessária. Rio de Janeiro, Paz e Terra.

RINGER, Fritz. (1995), El Ocaso de los Mandarines Alemanes. La Comunidad Académica Alemana, 1890-1933. Barcelona, Pomares-Corredor.

RODRÍGUEZ, Roberto e CASANOVA, Hugo. (1994), Universidad Contemporánea: Racionalidad Política y Vinculación Social. México, Centro de Estudios sobre la Universidad.

SALMI, Jamil. (2007), “The Challenge of Establishing World-Class Universities”. Disponível em http://portal.unesco.org/education/en/files/55825/12017990845Salmi. pdf/Salmi.pdf. Acessado em janeiro de 2009.

SALAS, Víctor. (2000), Presupuestos Universitarios y Financiamiento Público de las Universidades Tradicionales en Chile 1990-1999. Santiago de Chile, CPU.

SAMANIEGO, Augusto (ed.). (2007), Las Universidades Públicas. ¿Equidad en la Educación Superior Chilena? Santiago de Chile, LOM.

SCHERZ, Luis. (1968), El Camino de la Revolución Universitaria. Santiago de Chile, Editorial del Pacífico.

. (2005), La Universidad Chilena desde los Extramuros. Santiago de Chile, Universidad Alberto Hurtado.

SCHMAL, Rodolfo et alii. (2007), "Factores que Inciden en el Financiamiento de los Estudios Universitarios en Chile". Sociologias, ano 9, no 17, pp. 316-339.

SCHUGURENSKY, Daniel. (2007), "The Political Economy of Higher Education in the Time of Global Markets: Whither the Social Responsibility of the University?", in R. A. Rhoads e C. A. Torres (eds.), The University, State, and Market. The Political Economy of Globalization in the Americas. Stanford, Stanford University Press, pp. 301-320.

e NAIDORF, Judith. (2004), “Parceria Universidade-Empresa e Mudanças na Cultura Acadêmica: Análise Comparativa dos Casos da Argentina e do Canadá". Educação \& Sociedade, vol. 25, no 88, pp. 997-1022. 
SCHWARTZMAN, Simon. (1991), The Future of Higher Education in Brazil. Trabalho apresentado no XVI Congresso Internacional da Latin American Studies Association (Lasa). Washington, 4-6 de abril, pp. 1-31.

. (1992), "Non-Western Societies and Higher Education", in B. R. Clark e G. Neave (eds.), The Encyclopedia of Higher Education. Oxford, Pergamon, pp. 969-975.

. (1993), "Policies for Higher Education in Latin America: The Context". Higher Education, vol. 25, no 1, pp. 9-20.

. (2006), América Latina: Universidades en Transición. Washington, Organización de los Estados Americanos.

SERRANO, Sol. (1994), Universidad y Nación. Chile en el Siglo XIX. Santiago de Chile, Editorial Universitaria.

SHILS, Edward. (1976), Los Intelectuales y el Poder. Buenos Aires, Tres Tiempos.

e ROBERTS, John. (2004), “The Diffusion of European Models outside Europe”, in W. RÜEGG (ed.), A History of the University in Europe. Universities in the Nineteenth and Early Twentieth Centuries (1800-1945). Cambridge, Cambridge University Press, pp. 163-230.

SILVA MICHELENA, Héctor e SONNTAG, Heinz Rudolf. (1970), Universidad, Dependencia y Revolución. México, Siglo XXI.

SKILBECK, Malcom. (2001), The University Challenged: A Review of International Trends and Issues with Particular Reference to Ireland. Dublin, Higher Education Authority, pp. 1-15.

SLAUGHTER, Sheila e RHOADES, Gary. (2004), Academic Capitalism and the New Economy. Markets, State, and Higher Education. Baltimore/London, Johns Hopkins.

SMITH, Anthony e WEBSTER, Frank (eds.). (1997), The Postmodern University? Contested Visions of Higher Education in Society. Buckingham, Open University Press.

SOLARI, Aldo. (1967), “Los Movimientos Estudiantiles Universitarios en América Latina”. Revista Mexicana de Sociología, vol. 29, no 4, pp. 853-869.

(ed.). (1968), Estudiantes y Política en América Latina. Caracas, Monte Avila Editores.

STEGER, Hans-Albert. (1974), Las Universidades en el Desarrollo Social de América Latina. México, Fondo de Cultura Económica.

TEDESCO, Juan Carlos (ed.). (1986), La Juventud Universitaria en América Latina. Caracas, Cresalc/Unesco.

TEICHLER, Ulrich. (2007), "The Changing Patterns of the Higher Education Systems in Europe and the Future Tasks of Higher Education Research", in European Science Foundation (ed.), Higher Education Looking Forward: Relations between Higher Education and Society. Strasbourg, European Science Foundation, pp. 79-103.

TEIXEIRA, Pedro et alii (eds.). (2004), Markets in Higher Education. Rhetoric or Reality? Dordrecht, Kluwer Academic Publishing.

THAYER, William. (1996), La Crisis No Moderna de la Universidad Moderna: Epílogo del Conflicto de las Facultades. Santiago de Chile, Editorial Cuarto Propio. 
VÄLIMAA, Jussi e YLIJOKI, Oili-Helena (eds.). (2008), Cultural Perspectives on Higher Education. Dordrecht/London, Springer.

VASCONI, Tomás Amadeo. (1969), "Dependencias y Superestructura (Notas para un Programa de Trabajo)". Revista Mexicana de Sociología, vol. 31, no 4, pp. 795-816.

WEBER, Max. (1964), Economía y Sociedad. Esbozo de Sociología Comprensiva. México, Fondo de Cultura Económica.

WEILER, Hans. (2006), "Challenging the Orthodoxies of Knowledge: Epistemological, Structural, and Political Implications for Higher Education", in G. Neave (ed.), Knowledge, Power and Dissent. Critical Perspectives on Higher Education and Research in Knowledge Society. Paris, Unesco, pp. 61-87.

WILSON, Logan. (1942), The Academic Man: A Study in the Sociology of a Profession. New York, Oxford University Press.

WINSTON, Gordon C. (2000), “Economic Stratification and Hierarchy among U.S. Colleges and Universities". Discussion Paper no 58, Williams College, pp. 1-37. Disponível em http:/ / www.williams.edu/wpehe/DPs/DP-58.pdf. Acessado em janeiro de 2009.

. (2000a), "The Positional Arms Race in Higher Education". Discussion Paper no 54, Williams College, pp. 1-37. Disponível em http://www.williams.edu/wpehe/ DPs/DP-54.pdf. Acessado em janeiro de 2009.

. (2003), "Toward a Theory of Tuition: Prices, Peer Wages, and Competition in Higher Education". Discussion Paper no 65, Williams College, pp. 1-35. Disponível em http://www.williams.edu/wpehe/DPs/DP-65.pdf. Acessado em janeiro de 2009.

WORLD BANK. (2002), Constructing Knowledge Societies: New Challenges for Tertiary Education. Disponível em http://web.worldbank.org/WBSITE/EXTERNAL/ TOPICS / EXTEDUCATION / 0,,contentMDK:20283509 menuPK:617592 page PK:148956 piPK:216618 theSitePK:282386,00.html. Acessado em janeiro de 2009. 


\section{ABSTRACT \\ Sociology of Higher Education in the International, Regional, and Local Contexts}

This article analyzes the current development of the sociology of higher education in countries of the Northern Hemisphere, with an emphasis on the United States and Europe, as well as the field's progress in Spanish-speaking Latin American countries, Chile in particular. The author reviews the processes of academic institutionalization and research professionalization and output in the central countries and its subsequent evolution by geographic diffusion, inclusion of new themes, interdisciplinary emphasis, differentiation, and specialization of approaches due to growth in comparative studies of national systems. The article also identifies weaknesses in these same processes of academic institutionalization, professionalization, and research output in Latin America, in contrast with the region's contribution in terms of key characteristic perspectives and study topics.

Key words: higher education; field of study; academic research; public policies

\section{RÉSUMÉ}

Sociologie de l'Éducation Supérieure dans les Domaines International, Régional et Local

Dans cet article, on examine l'état de développement de la sociologie de l'éducation supérieure dans les pays de l'hémisphère nord - surtout aux États-Unis et en Europe - et son niveau d'implantation dans l'Amérique latine hispanophone, surtout au Chili. On revisite les processus $\mathrm{d}$ 'institutionnalisation universitaire, la professionnalisation de la recherche et la production de cette discipline dans les pays centraux, ainsi que son évolution due à la diffusion géographique, à l'inclusion de nouveaux thèmes de recherche, de confluences interdisciplinaires, de différenciation et spécialisation d'approches résultant d'un nombre croissant de perspectives comparatives dans l'étude des systèmes nationaux. On voit aussi les points faibles de ces processus d'institutionnalisation, de professionnalisation et de production en Amérique latine à l'opposé de l'apport que cette région fournit sur d'autres thèmes et études.

Mots-clé: éducation supérieure; domaine d'études; recherche universitaire; politiques publiques 